\title{
Immunohistochemical expression and prognostic value of PD-L1 in Extrapulmonary small cell carcinoma: a single institution experience
}

Mohammed Salhab ${ }^{1 *}$, Yazan Migdady², Melanie Donahue ${ }^{1}$, Yiqin Xiong ${ }^{3}$, Karen Dresser ${ }^{3}$, William Walsh ${ }^{1}$, Benjamin J. Chen ${ }^{3}$ and James Liebmann ${ }^{4}$

\begin{abstract}
Background: Extrapulmonary small cell carcinomas (ESCC) are rare but aggressive tumors. Relapses are common despite treatment with chemotherapy and/or radiotherapy. Prospective data for treatment of ESCC are lacking; treatment of these cancers usually incorporates lung small cell carcinoma treatment recommendations. Cancer staging remains the most important prognostic factor. Cancer immunotherapy targeting the PD-1/PD-L1 pathway has shown efficacy in multiple tumor types, and could be an appealing treatment strategy for these rare tumors.

Methods: We investigated PD-L1 expression by immunochemistry (IHC) in ESCCs diagnosed at University of Massachusetts Medical Center, from 1999 to 2016. 34 cases with sufficient material were selected for PD-L1 IHC analysis using clone E1L3N. PD-L1 expression was evaluated using the combined positive score (CPS). Retrospective chart review was performed. We evaluated the incidence and prognostic value of PD-L1 expression in ESCC at our institution.

Results: Twelve out 34 cases (35\%) had PD-L1 CPS scores $\geq 1$. Ten cases had CPS scores ranging 1-5, whereas 2 cases had CPS scores $>80$. The overall response rate to the standard chemotherapy with/without radiotherapy in the PD-L1 positive group was $80 \%$ versus $67 \%$ for the PDL-1 negative group ( $p$-value 0.67 ). The median overall survival for the PD-L1 positive group, regardless of stage, was 11.5 months versus 7 months for PD-L1 negative group ( $p$-value 0.34 ). Patients with limited stage disease with positive PD-L1 had a median survival of 53 months compared to 15 months for patients with PD-L1 negative limited stage ( $p$-value 0.80).

Conclusions: This study showed that at least one third of our ESCC tissue samples expressed PD-L1. There was a trend for higher response rates to the standard chemotherapy with/without radiotherapy and improved survival in PD-L1 positive patients. Further studies are required to understand the implications of immune dysregulation in these aggressive tumors. PD-L1/PD-1 inhibitors should be investigated in this group of patients.
\end{abstract}

Keywords: Extrapulmonary small cell carcinomas, PD-L1 expression and prognostic value, Combined positive score

\footnotetext{
* Correspondence: dr_mms2010@hotmail.com

'Department of Medicine, Hematology and Oncology division, University of Massachusetts Medical School, 55 N lake avenue, Worcester, MA 01655, USA Full list of author information is available at the end of the article
}

(C) The Author(s). 2018 Open Access This article is distributed under the terms of the Creative Commons Attribution 4.0 International License (http://creativecommons.org/licenses/by/4.0/), which permits unrestricted use, distribution, and reproduction in any medium, provided you give appropriate credit to the original author(s) and the source, provide a link to the Creative Commons license, and indicate if changes were made. The Creative Commons Public Domain Dedication waiver (http://creativecommons.org/publicdomain/zero/1.0/) applies to the data made available in this article, unless otherwise stated. 


\section{Background}

Extrapulmonary small cell carcinomas (ESCC) have an aggressive nature characterized by early, widespread metastases. These cancers are rare with a reported incidence of 0.1 to $0.4 \%$ in North America and represent up to $5 \%$ of all cases of small cell carcinoma [1]. The median survival for limited and extensive disease ranges from 1.4 to 3.5 years and 8 to 12 months, respectively. The overall 5 -year survival rate is less than $15 \%$ for limited stage patients $[1,2]$.

Disease stage, either limited or extensive, remains the most important prognostic factor for these cancers [3]. Site of origin of ESCC may also impact prognosis. The most commonly reported primary sites of disease are the gastrointestinal tract, genitourinary system, and ESCC of unknown primary tumor $[3,4]$.

Most treatment recommendations are derived from small single-institution experiences or extrapolated from pulmonary small cell cancer as prospective trials are lacking for this disease $[5,6]$. Multimodality treatment with platinum based chemotherapy with radiation and/or surgery is the most commonly used initial treatment approach for limited stage disease, while platinum based chemotherapy with etoposide is the most widely used regimen for extensive stage patients [5-9]. Despite aggressive initial therapy, most patients with ESCC will relapse with metastatic disease within a year of initial treatment $[5,6]$.

Cancer immunotherapy targeting the PD-1/PD-L1 pathway is not yet established for ESCC. We evaluated the incidence and the prognostic value of PD-L1 expression in ESCC at our institution. To our knowledge no studies have investigated the value of PD-L1 testing in ESCC.

\section{Methods}

Institutional review board (IRB) approval was obtained. We investigated PD-L1 expression by immunochemistry (IHC) in ESCC diagnosed at University of Massachusetts Medical Center between 1999 and 2016. Forty-five patients with ESCC were identified. From these patients, 34 had specimens with sufficient material for PD-L1 IHC analysis. Specimens included cytology cell blocks, needle core biopsies, and whole tissue sections from resection specimens.

Patients included for analysis had a pathologic diagnosis of ESCC and no evidence of lung disease based on chest CT scan at time of diagnosis. Pathologic diagnosis included morphology consistent with small cell carcinoma, and/or positive immunohistochemical staining with synaptophysin, chromogranin, and/or CD56. Well-differentiated neuroendocrine tumors, including carcinoid tumors, were excluded. Disease stage was classified as extensive (ED) or limited (LD), using the Veterans' Affairs Lung Study Group criteria, by reviewing radiologic records [10]. LD was defined as tumor confined to the primary site and regional lymph nodes. ED was defined as tumor extending beyond loco-regional boundaries. Chart reviews were conducted to assess treatment modalities, age at diagnosis, staging, site of origin, response to treatment, and survival. Response to treatment was defined as at least partial response, based on RECIST (Response Evaluation Criteria In Solid Tumors) criteria [11].

Immunohistochemical studies were performed on 5-um sections of formalin-fixed, paraffin-embedded tissue. Slides were first deparaffinized, and rehydrated. Antigen retrieval was carried out with $0.01 \mathrm{M}$ citrate buffer at $\mathrm{pH}$ 6.0. Slides were heated in a $770-\mathrm{W}$ microwave oven for $14 \mathrm{~min}$, cooled to room temperature, and rinsed in distilled water before staining. All the slides were stained on the Dako Autostainer (Dako Corporation, Carpinteria, CA). The sections were first blocked for endogenous peroxidase activity with an application of Dual Endogenous Block (Dako) for $10 \mathrm{~min}$, followed by a brief buffer wash. The slides were then incubated with primary antibody for $30 \mathrm{~min}$. The rabbit monoclonal antibody to PD-L1 (clone E1L3N, Cell Signaling, \#13684) was used at a dilution of 1:500, and diluted with Dako Antibody Diluent (Dako). Following a buffer rinse, sections were incubated with Ultraview Detection (Ventana Medical Systems, Tuscon, AZ) for $30 \mathrm{~min}$. The sections were washed, and treated with a solution of diaminobenzidine and hydrogen peroxide (Dako) for $10 \mathrm{~min}$, to produce the visible brown pigment. After rinsing, a toning solution (DAB Enhancer, Dako) was used for $2 \mathrm{~min}$ to enrich the color. Following rinsing, the sections were counterstained with hematoxylin, dehydrated, and cover slipped with permanent media. Sections of tonsil, placenta, and classical Hodgkin lymphoma tissue with known positivity for PD-L1 were used as positive controls for staining.

PD-L1 IHC scoring was performed using the combined positive score (CPS), previously described for the scoring of PD-L1 in esophageal adenocarcinoma [12, 13]. CPS is defined as the total number of PD-L1 positive cells (tumor, lymphocytes, and macrophages) divided by the total number of tumor cells. The average CPS of 2 hotspots in each sample was recorded. Two pathologists independently reviewed the IHC studies with agreement in most cases ( $>80 \%$ ), followed by discussion to arrive at a consensus in the remaining cases. CPS $\geq 1$ was considered positive.

\section{Statistical analysis}

All survival and subgroup analyses were performed using GraphPad Prism software, with curve comparisons performed using log-rank (Mantel-Cox) tests. Kaplan-Meier survival curves were generated using GraphPad Prism software. Response rates to treatment were compared using Fisher test with $p>0.05$ accepted as statistically significant.

\section{Results}

Demographic characteristics of the patients and the site of origin of their cancers are shown in Table 1 . The most 
Table 1 Baseline characteristics of ESCC patients

\begin{tabular}{ll}
\hline Characteristics & Number (\%) \\
\hline Total patients ( $\mathrm{n})$ & 34 \\
Age & 68 \\
$\quad$ Median & $20-86$ \\
Range & \\
Sex & $19(56 \%)$ \\
Male & $15(44 \%)$ \\
Female & \\
Stage & $11(32 \%)$ \\
Limited & $23(68 \%)$ \\
Extensive & \\
Localization & $18(53 \%)$ \\
Genitourinary & $10(29 \%)$ \\
Unknown primary & $5(15 \%)$ \\
Gastrointestinal & $1(3 \%)$ \\
Other (Palate)
\end{tabular}

common confirmed primary sites were from the genitourinary tract. However, cancers of unknown primary origin constituted the second most common group.

Twelve specimens (35\%) showed positive PD-L1 expression (CPS $\geq 1$, Fig. 1). Of the positive specimens, 2 showed diffuse PD-L1 expression in both tumor and stromal cells with CPS $>80$. One of these cases arose from the ureter and the other from the gall bladder. The other 10 specimens that were considered positive had CPS scores of $1-5$, primarily due to focal positive staining of non-tumor immune cells adjacent to the tumor. Twenty-two cases (65\%) were negative for PD-L1 expression (CPS < 1).

All patient with limited stage received a bimodality treatment with chemoradiation. Fifty-six percent of extensive stage patients received chemotherapy. One patient received platinum and irinotecan, while all other patients with extensive disease who received chemotherapy were treated with platinum and etoposide. The other $46 \%$ of patients with extensive stage disease received only supportive care with no chemotherapy; $15 \%$ of those patients declined chemotherapy, 9\% expired before obtaining the final pathology read but received supportive care while in the intensive care unit, and the remainder had very poor
A. Case \#4 (ovary), CPS $<1$.
B. Case \#13 (bladder), CPS $=5$.
C. Case $\# 31$ (ureter), $\mathrm{CPS}=80$.

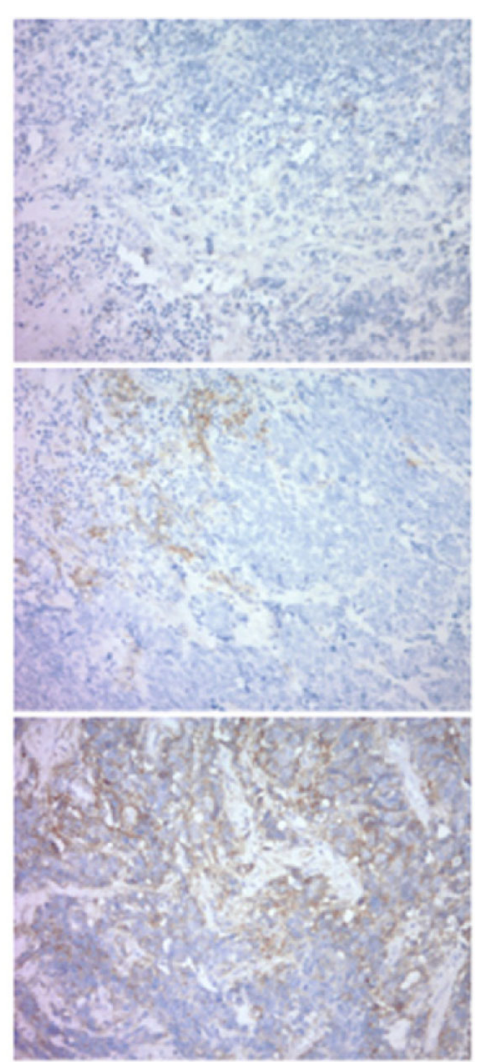

Fig. 1 Examples of extrapulmonary small cell carcinoma stained for PD-L1 expression graded by combined positive score 
Table 2 The overall response rate and median survival between PD-L1 positive and negative groups across all cancer stages

\begin{tabular}{llll}
\hline & $\begin{array}{l}\text { PD-L1 positive } \\
(n=12)\end{array}$ & $\begin{array}{l}\text { PD-L1 negative } \\
(n=22)\end{array}$ & $\begin{array}{l}P \\
\text { value }\end{array}$ \\
\hline $\begin{array}{l}\text { Received treatment } \\
\text { Response rates to }\end{array}$ & $10(83 \%)$ & $16(73 \%)$ & \\
$\begin{array}{l}\text { treatment } \\
\begin{array}{l}\text { Median overall } \\
\text { survival (mo.) }\end{array}\end{array}$ & 11.5 & $11(67 \%)$ & 0.67 \\
\hline
\end{tabular}

performance status with advanced age. Fifteen percent patients had surgical resection of their primary cancer, in the setting of a diagnostic evaluation. The overall response rate in the PD-L1 positive group was $80 \%$ versus $67 \%$ in the PD-L1 negative group ( $p$-value 0.67 ) [Table 2]. The median overall survival for the PD-L1 positive group, regardless of stage, was 11.5 months versus 7 months for the PD-L1 negative group ( $p$-value 0.34) [Fig. 2]. Patients with limited stage disease with positive PD-L1 staining had a median 53 months overall survival compared to PD-L1 negative patients with limited disease whose median overall survival was 15 months ( $p$-value 0.80) [Table 3]. Extensive stage patients had median overall survival that was similar between PD-L1 positive and negative groups, 4 months vs 5 months respectively ( $p$-value 0.50 ).

Of the 25 patients who relapsed, 14 patients relapsed after 2007 when the FDA approved Topotecan for relapsed small cell carcinoma of the lung. Two Patients declined additional chemotherapy, two patients received Topotecan without any response and the remaining 10 patients progressed rapidly and didn't get treated due to poor performance status. None of the patients received second line chemotherapy before 2007 .

\section{Discussion}

Our data showed that 35\% of ESCC tumor samples were positive for $\mathrm{PD}-\mathrm{L} 1(\mathrm{CPS} \geq 1)$. PD-L1 positive tumors showed a trend toward improved median overall survival and there was separation of survival curves between the PD-L1 positive and negative groups at around 1 year, though not statistically significant.

Treatment of ESCC tends to follow the treatment plan utilized for small cell lung cancer. First line treatment with platinum-based chemotherapy remains the standard. Second line treatments are lacking for all patients with small cell carcinomas, regardless of tissue of origin, with topotecan as the only FDA approved drug in the second line setting [14]. Immunotherapy is a promising treatment for small cell carcinomas. PD-L1 inhibitors have been investigated in small cell lung cancer in a phase IB study (NCT02054806) as second line therapy. In that trial, 20 patients with SCLC expressing PD-L1 by immunohistochemistry were treated with pembrolizumab. Objective responses were observed in seven cases (35\%) [15]. Both nivolumab and ipilimumab have also demonstrated activity in early-phase clinical studies. In a phase II study, 216 patients were assigned to treatment with nivolumab or nivolumab plus ipilimumab at three different dose combinations. An objective response was achieved in $10 \%$ of patients receiving nivolumab only versus $21 \%$ of patients receiving both nivolumab and ipilimumab at any dose combination [16].

PD-1/PD-L1 inhibition has shown efficacy in a variety of malignancies in both first line and subsequent therapy [17-19]. Many trials have attempted to identify subsets of patients who are most likely to benefit from PD-L1 checkpoint inhibition by assessing PD-L1 expression in tumor specimens and/or tumor microenvironment. Cancers with high PD-L1 expression have consistently demonstrated a higher response rate to PD-1/PD-L1 antibodies than cancers that lack PD-L1 expression, although the use of such inhibitors are not limited to the positive expressers. The use and pitfalls of PD-L1 assays

\section{Survival (months) of ESCC patients with PD-L1 positive versus negative staining of tumors}
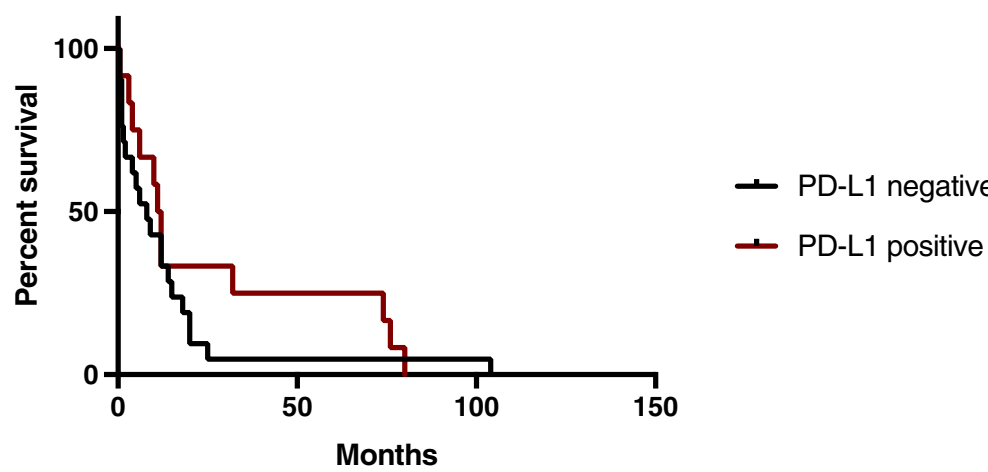

Fig. 2 Overall survival (months) of ESCC patients in PD-L1 positive versus negative groups ( $p$ 0.34) 
Table 3 The overall response rate and median survival between limited stage PD-L1 positive and negative groups

\begin{tabular}{llll}
\hline & \multicolumn{2}{l}{ Limited stage disease } & $P$ \\
\cline { 2 - 3 } & PD-L1 positive & PD-L1 negative & value \\
& $(n=6)$ & $(n=5)$ & \\
\hline Male sex (\%) & $4(66 \%)$ & $2(40 \%)$ & \\
Received treatment & $6(100 \%)$ & $5(100 \%)$ & \\
Response rates to treatment & $6(100 \%)$ & $5(100 \%)$ & \\
Alive at 1 year & $6(100 \%)$ & $4(80 \%)$ & 0.80 \\
Median overall survival (mo.) & 53 & 15 & \\
\hline
\end{tabular}

have been reviewed recently [20]. As it remains controversial regarding which scoring system is preferable to grade the expression, we used the CPS because of the recent trend in using this scoring in other tumors mainly gastrointestinal $[12,13]$. We aimed to provide more information about the tumor cells and their microenvironment (lymphocytes, and macrophages), for this unstudied area of such a rare disease.

Tumor PD-L1 status may provide prognostic or predictive information. A recently published clinical trial conducted in patients with advanced non-squamous, non-small-cell lung cancer, demonstrated a higher response rate to chemotherapy in patients whose tumors had high expression of PD-L1 compared to patients whose tumors failed to express PD-L1 [21, 22]. Similarly, in our study, ESCC with PD-L1 expression showed higher response rates to chemotherapy than ESCC that lacked PD-L1 expression. Additionally, in our study patients whose tumors tested positive for PD-L1 had improved median overall survival compared with patients whose tumors did not express PD-L1. The lack of statistical significance in differences of overall survival likely reflects the small sample size in this single institution review of patients with a rare malignancy. While disease staging and the site of origin of ESCC remain the most important prognostic factors, these results suggest that PD-L1 expression could be a predictive variable for prognosis and response to chemotherapy in ESCC.

The proposed rational of improved responses in patients with PD-L1 expression could be related to the presence of lymphocytes at the microenvironment of the tumor cells which could be of help to initiate apoptosis and inflammatory reaction, thus enhancing tumor response to chemotherapy and radiation. It is possible that the enhanced cytotoxicity of combination therapy could be due to the release of tumor neoantigens from cells killed by chemotherapy. Combining immunotherapy with chemotherapy as an upfront treatment is of interest at this point for all small cell carcinomas as chemotherapy showed the potential to increase the PD-L1 expression within the tumor microenvironment, which will enhance the responses to PD-1 inhibitors [23-25].

\section{Conclusion}

In conclusion, this study demonstrates the incidence of PD-L1 expression in a small cohort of ESCC, and suggests that PD-L1 expression in ESCC may be of prognostic and predictive relevance. Further studies are required to understand the implications of immune dysregulation in these aggressive tumors. PD-L1/PD-1 inhibitors should be investigated in this group of patients given the positive expression of PD-L1 in one third of patients in our review.

\section{Abbreviations}

CPS: Combined positive score; ED: Extensive; ESCC: Extrapulmonary small cell carcinomas; IHC: Immunochemistry; LD: Limited; RECIST: Response evaluation criteria in solid tumors

\section{Acknowledgements}

Data were presented SITC as a poster(p439), Maryland 2017.

\section{Availability of data and materials}

The datasets used and/or analyzed during the current study available from the corresponding author on reasonable request.

\section{Authors' contributions}

MS generated the idea, gathered data and wrote manuscript. YM wrote part of Manuscript. MD performed analysis and wrote manuscript. YX, KD and BC performed specimen staining and obtained results. WW reviewed manuscript. BC and JM senior authors and wrote manuscript. All authors read and approved the final manuscript.

\section{Ethics approval and consent to participate}

This study was reviewed and approved by the Institutional Review Board at University of Massachusetts Medical School/Medical Center.

\section{Competing interests}

The authors declare that they have no competing interests.

\section{Publisher's Note}

Springer Nature remains neutral with regard to jurisdictional claims in published maps and institutional affiliations.

\section{Author details}

'Department of Medicine, Hematology and Oncology division, University of Massachusetts Medical School, 55 N lake avenue, Worcester, MA 01655, USA. ${ }^{2}$ Pathology Department, Transfusion Medicine, Stanford School of Medicine, Stanford Hospital, 300 Pasteur Drive, Rm H1402, Stanford, CA 94305-5626, USA. ${ }^{3}$ Pathology Department, University of Massachusetts Medical School, 55 N lake avenue, Worcester, MA 01655, USA. ${ }^{4}$ Lahey Hospital \& Medical Center, Hematology and Oncology, Burlington, MA, USA.

Received: 13 February 2018 Accepted: 15 May 2018

Published online: 29 May 2018

\section{References}

1. Wong YNS, Jack RH, Mak V, Henrik M, Davies EA. The epidemiology and survival of extrapulmonary small cell carcinoma in south East England, 1970-2004. BMC Cancer. 2009;9:209.

2. Ochsenreither S, Marnitz-Schultze S, Schneider A, et al. Extrapulmonary small cell carcinoma (EPSCC): 10 years' multi-disciplinary experience at Charité. Anticancer Res. 2009;29:3411.

3. Walenkamp AM, Sonke GS, Sleijfer DT. Clinical and therapeutic aspects of extrapulmonary small cell carcinoma. Cancer Treat Rev. 2009;35:228.

4. Terashima T, Morizane C, Hiraoka N, et al. Comparison of chemotherapeutic treatment outcomes of advanced extrapulmonary neuroendocrine carcinomas and advanced small-cell lung carcinoma. Neuroendocrinology. 2012;96:324

5. Brennan SM, Gregory DL, Stillie A, et al. Should extrapulmonary small cell cancer be managed like small cell lung cancer? Cancer. 2010;116:888. 
6. Annemiek ME, Walenkamp A, Gabe S, Sonke B, Sleijfer DT. Clinical and therapeutic aspects of extrapulmonary small cell carcinoma. Cancer Treat Rev. 2009;35:228-36.

7. Soto $D E$, Eisbruch A. Limited-stage extrapulmonary small cell carcinoma: outcomes after modern chemotherapy and radiotherapy. Cancer J. 2007; 13(4):243-6.

8. Sengoz M, Abacioglu U, Salepci T, Eren F, Yumuk F, Turhal S. Extrapulmonary small cell carcinoma: multimodality treatment results. Tumori. 2003;89(3):274.

9. Kim JH, Lee SH, Park J, Kim HY, Lee SI, Nam EM, Park JO, Kim K, Jung CW, Im YH, Kang WK, Lee MH, Park K. Extrapulmonary small-cell carcinoma: a singleinstitution experience. J.jn J Clin Oncol. 2004;34(5):250.

10. Hansen HH, Dombernowsky P, Hirsch FR. Staging procedures and prognostic features in small cell anaplastic bronchogenic carcinoma. Semin Oncol. 1978:5:280-7.

11. Eisenhauer E, Therasse P, Bogaerts J, Schwartz LH, Sargent D, Ford R, Dancey J, et al. New response evaluation criteria in solid tumours: revised RECIST guideline (version 1.1). Eur J Cancer. 2009;45:228-47.

12. Kulangara K, Hanks DA, Waldroup S, Peltz L, Shah S, Roach C, Juco JW, Emancipator K, Stanforth D. Development of the combined positive score (CPS) for the evaluation of PD-L1 in solid tumors with the immunohistochemistry assay PD-L1 IHC 22C3 pharmDx. J Clin Oncol. 2017:35:15.

13. Muro K, Chung HC, Shankaran V, Geva R, Catenacci D, Gupta S, Eder JP, Golan T, Le DT, Burtness B, McRee AJ, Lin C-C, Pathiraja K, Lunceford J, Emancipator K, Juco J, Koshiji M, Bang Y-J. Pembrolizumab for patients with PD-L1-positive advanced gastric cancer (KEYNOTE-012): a multicentre, openlabel, phase 1b trial. Lancet Oncol. 2016;17:717-26.

14. O'Brien ME, Ciuleanu TE, Tsekov H, Shparyk Y, Cuceviá B, Juhasz G, Thatcher N, Ross GA, Dane GC, Crofts T. Phase III trial comparing supportive care alone with supportive care with oral topotecan in patients with relapsed small-cell lung cancer. J Clin Oncol. 2006;24(34):5441.

15. Ott PA, Elez E, Hiret S, Kim DW, Morosky A, Saraf S, Piperdi B, Mehnert JM. Pembrolizumab in patients with extensive-stage small-cell lung Cancer: results from the phase Ib KEYNOTE-028 study. J Clin Oncol. 2017;35(34):3823-9.

16. Antonia SJ, López-Martin JA, Bendell J, et al. Nivolumab alone and nivolumab plus ipilimumab in recurrent small-cell lung cancer (CheckMate 032): a multicentre, open-label, phase 1/2 trial. Lancet Oncol. 2016:17(7):883.

17. Reck M, Rodríguez-Abreu D, Robinson AG, Hui R, Csőszi T, Fülöp A, Gottfried M, Peled N, Tafreshi A, Cuffe S, O'Brien M, Rao S, Hotta K, Leiby MA, Lubiniecki GM, Shentu Y, Rangwala R, Brahmer JR, KEYNOTE-024 Investigators. Pembrolizumab versus chemotherapy for PD-L1-positive nonsmall-cell lung Cancer. N Engl J Med. 2016;375(19):1823.

18. Garon EB, Rizvi NA, Hui R, KEYNOTE-001 investigators. Pembrolizumab for the treatment of non-small-cell lung cancer. N Engl J Med. 2018:372(21):2015.

19. Borghaei $H$, Paz-Ares $L$, Horn L, et al. Nivolumab versus docetaxel in advanced nonsquamous non-small-cell lung Cancer. N Engl J Med. 2015; 373(17):1627.

20. Ilie M, Hofman V, Dietel M, et al. Assessment of the PD-L1 status by immunohistochemistry: challenges and perspectives for therapeutic strategies in lung cancer patients. Virchows Arch. 2016:468:511.

21. Rittmeyer A, Barlesi F, Waterkamp D, OAK Study Group. Atezolizumab versus docetaxel in patients with previously treated non-small-cell lung cancer (OAK): a phase 3, open-label, multicentre randomised controlled trial. Lancet. 2017;389(10066):255.

22. Langer CJ, Gadgeel SM, Borghaei H, Papadimitrakopoulou VA, Patnaik A, Powell SF, Gentzler RD, Martins RG, Stevenson JP, Jalal SI, Panwalkar A, Yang JC, Gubens M, Sequist LV, Awad MM, Fiore J, Ge Y, Raftopoulos H, Gandhi L, KEYNOTE-021 investigators. Carboplatin and pemetrexed with or without pembrolizumab for advanced, non-squamous non-small-cell lung cancer: a randomised, phase 2 cohort of the open-label KEYNOTE-021 study. Lancet Oncol. 2016:17(11):1497.

23. Derer A, Spiljar M, Bäumler M, Hecht M, Fietkau R, Frey B, Gaipl US. Chemoradiation Increases PD-L1 expression in certain melanoma and glioblastoma cells. Front Immunol. 2016;7:610.

24. Lim SH, Hongb M, Ahnc S, et al. Changes in tumour expression of programmed death-ligand 1 after neoadjuvant concurrent chemoradiotherapy in patients with squamous oesophageal cancer. Eur J Cancer. 2016;52:1-9.

25. Wen S, Huang D, Ba Y, Li H, Liu R. The status of PD-L1 expression and TILs among ESCC patients in China and changes after radiation and chemotherapy. J Clin Oncol. 2017:35:15.

\section{Ready to submit your research? Choose BMC and benefit from:}

- fast, convenient online submission

- thorough peer review by experienced researchers in your field

- rapid publication on acceptance

- support for research data, including large and complex data types

- gold Open Access which fosters wider collaboration and increased citations - maximum visibility for your research: over $100 \mathrm{M}$ website views per year

At BMC, research is always in progress.

Learn more biomedcentral.com/submissions 